\title{
Does Size Really Matter? The Role of Tonotopic Map Area Dynamics for Sound Learning in Mouse Auditory Cortex
}

\author{
Hans Sperup Brünner, ${ }^{1, *}$ and ${ }^{\circledR}$ Rune Rasmussen ${ }^{2, *}$ \\ DOI:http://dx.doi.org/10.1523/ENEURO.0002-17.2017 \\ ${ }^{1}$ Department of Biomedicine, Basel University, Basel 4056, Switzerland, ${ }^{2}$ The Danish Research Institute of \\ Translational Neuroscience - DANDRITE, Nordic EMBL Partnership for Molecular Medicine, Department of \\ Biomedicine, Aarhus University, Aarhus C 8000, Denmark
}

\begin{abstract}
This commentary centers on the novel findings by Shepard et al. (2016) published in eNeuro. The authors interrogated tonotopic map dynamics in auditory cortex (ACtx) by employing a natural sound-learning paradigm, where mothers learn the importance of pup ultrasonic vocalizations (USVs), allowing Shepard et al. to probe the role of map area expansion for auditory learning. They demonstrate that auditory learning in this paradigm does not rely on map expansion but is facilitated by increased inhibition of neurons tuned to low-frequency sounds. Here, we discuss the findings in light of the emerging enthusiasm for cortical inhibitory interneurons for circuit function and hypothesize how a particular interneuron type might be causally involved for the intriguing results obtained by Shepard et al.
\end{abstract}

Key words: auditory cortex; inhibition; interneurons; learning; plasticity; tonotopic map

\section{Significance Statement}

This commentary centers on the novel findings by Shepard et al. (2016) published in eNeuro. The authors interrogated tonotopic map dynamics in auditory cortex (ACtx) by employing a natural sound-learning paradigm, where mothers learn the importance of pup ultrasonic vocalizations (USVs), allowing Shepard et al. to probe the role of map area expansion for auditory learning. They demonstrate that auditory learning in this paradigm does not rely on map expansion but is facilitated by increased inhibition of neurons tuned to low-frequency sounds. Here, we discuss the findings in light of the emerging enthusiasm for cortical inhibitory interneurons for circuit function and hypothesize how a particular interneuron type might be causally involved for the intriguing results obtained by Shepard et al.

SOUNDS GUIDE MOST OF OUR EVERYDAY BEHAVIORS, and the first cortical area that receives sound-evoked barrages is the auditory cortex (ACtx). A cardinal task for ACtx is to encode, process, and transmit species-specific communication sounds from the surrounding environment (Rauschecker, 1998; Scott and Johnsrude, 2003). How ACtx circuits are persistently modified by experience to encode relevant tones represents a great ongoing challenge to neuroscience.

Received January 3, 2017; accepted January 4, 2017; First published February 08, 2017.

The authors declare no competing financial interests.

Author Contributions: H.B. and R.R. drafted and wrote the paper.

${ }^{*}$ H.B. and R.R. contributed equally to this work.
Most primary sensory cortices are characterized by their topographical organization where nearby neurons tend to respond to similar sensory stimuli, such as orientation columns in visual cortex (Hubel and Wiesel, 1974, 1977) or the sensory homunculus in sensory cortex (Penfield and Boldrey, 1937). The same organizational principle applies for ACtx and is organized such that tones of similar frequency activate neighboring neurons yielding a tonotopic map

Acknowledgements: We thank Eva Meier Carlsen for valuable discussions and comments on this manuscript.

Correspondence should be addressed to Rune Rasmussen at the above address, E-mail: runerasmussen@dandrite.au.dk. 
(Winer et al., 2005; Barkat et al., 2011). This map is not constant, and like the rest of the cerebral cortex, ACtx organization is plastic. Investigating experience-dependent plasticity in ACtx has a long history and decades of experimental work have led to the concept of tonotopic map plasticity (Pienkowski and Eggermont, 2011; Schreiner and Polley, 2014). Prolonged, passive exposure to tones at specific frequencies during development and adulthood can profoundly increase the areas of the ACtx tonotopic map containing neurons responding to those particular frequencies (Weinberger, 1997, 2004; Bieszczad and Weinberger, 2010; Barkat et al., 2011; Kurkela et al., 2016). Such evidence has fostered the hypothesis that increases in map area represent the structural substrate underlying auditory memory formation in ACtx (Rutkowski and Weinberger, 2005). If this hypothesis is exclusively true, one should not be able to observe auditory memory formation without concomitant tonotopic map area expansion. However, conflicting data to this argument have emerged, and studies have demonstrated that sound experience-dependent auditory memory formation can occur in the absence of ACtx map area expansion (Galindo-Leon et al., 2009). Hence, one might entertain the hypothesis that tonotopic map expansion is not a requirement for auditory memory formation. Alternatively, tonotopic map reorganization might occur transiently and, therefore, might not always manifest in lasting map area increases. Evidently the causal and mechanistic function of tonotopic map plasticity and in particular area expansion, for behaviorally relevant learning, is still unresolved and an issue of debate. In an article published in eNeuro, Shepard et al. (2016) explored tonotopic map dynamics occurring in ACtx in a natural sound-learning paradigm, where mouse mothers learn the importance of pup ultrasonic vocalizations (USVs), allowing the authors to probe the causal role of map area expansion for auditory learning and memory formation.

To answer whether a lasting or transient tonotopic map expansion occur during maternal experience in mice, Shepard et al. (2016) mapped ACtx of naïve mice and compared this with maternal mice at three different postnatal time points, namely 3-4, 9-10, and $21 \mathrm{~d}$ after parturition. ACtx mapping was conducted by recording multiunit activity in the thalamorecipient cortical layer 4 while playing pure tones $(4-80 \mathrm{kHz})$, revealing spatial processing areas of distinct tones in ACtx. These experiments demonstrated that during all studied time points of maternal experience, the ACtx representation of ultrasound frequencies did not change, suggesting that neither transient nor lasting map reorganization occurred. This intriguing result led the authors to explore neuronal spiking activity of principal cells during ultrasonic auditory stimuli within distinct ACtx regions tuned to best frequencies of either above or below $40 \mathrm{kHz}$. During exposure to ultrasound frequencies $(65-80 \mathrm{kHz})$ or pup USVs, in regions tuned to high frequencies, neurons did not

DOI:http://dx.doi.org/10.1523/ENEURO.0002-17.2017

Copyright @ 2017 Brünner and Rasmussen

This is an open-access article distributed under the terms of the Creative Commons Attribution 4.0 International, which permits unrestricted use, distribution and reproduction in any medium provided that the original work is properly attributed. alter their spike rate, but interestingly, in regions tuned to low frequencies, neurons displayed greater spike rate suppression at all time points compared with naîve mice. This effect produced an enlarged contrast in spike rate between ACtx neural ensembles with high and low best frequencies in mothers exposed to ultrasound frequencies.

The findings by Shepard et al. (2016) elegantly demonstrate that learning the importance of pup USVs is not encoded and represented by ACtx tonotopic map expansion nor is caused by increased spiking of principal cells tuned to high frequencies. Rather, it appears that learning is represented by ultrasound frequency-dependent suppression of principal cells tuned to low frequencies, resulting in an enhanced signal-to-noise ratio in ACtx. This is an important observation supporting the idea that auditory learning does not invariably require tonotopic map reorganization or enhanced firing of neurons tuned to the learned sound (Galindo-Leon et al., 2009). Thus, the work by Shepard et al. (2016) challenges the classical view that experiencedependent learning in sensory cortices is encoded by expansion of map area devoted to that particular stimulus. Alternatively, as proposed by Shepard et al. (2016), ACtx plasticity might be orchestrated by changes in intra-cortical inhibitory barrages onto principal cells, thus enhancing the contrast between spiking in regions tuned to high and low frequencies.

In cortex, inhibitory barrages and overall inhibitory tone is regulated by local interneurons (Harris and Mrsic-Flogel, 2013; Allene et al., 2015). The importance of interneurons for shaping and modulating sensory representation and encoding has recently been described in primary visual cortex, where interneurons proved causally involved in forms of visual plasticity (Kaplan et al., 2016). Hence, it appears plausible and intriguing to speculate that interneurons could be equally important for auditory learning in ACtx. To experimentally interrogate the role of interneurons in auditory learning one needs to selectively manipulate these and relate this to the functional consequences (Kato et al., 2015). Cortical interneurons come in many flavors and contribute differentially to circuit function. Parvalbumin-positive $\left(\mathrm{PV}^{+}\right)$is one of three major classes of interneurons found the cortex, and these make perisomatic synapses onto principal cells in multiple layers (Allene et al., 2015). The two other major classes of interneurons include vasoactive intestinal peptide- and somatostatin-positive interneurons, which form connections with other interneurons and dendrites of principal cells, respectively (Harris and Mrsic-Flogel, 2013). The perisomatic synapses of $\mathrm{PV}^{+}$interneurons position them favorable for potently influencing the spiking of principal cells (Allene et al., 2015), and we hypothesize that PV ${ }^{+}$ interneurons might be a key player enhancing the activity contrast between neurons tuned to high and low frequencies in response to ultrasound frequencies, as observed by Shepard et al. (2016). Such a hypothesis can now be explored with cell-type specificity and high temporal control due to the development and revolution of optogenetical methods (Deisseroth, 2015). A future experiment of relevance would thus be to locally activate or inhibit $\mathrm{PV}^{+}$interneurons using optogenetics while recording the response to ultrasound frequencies in ACtx in maternal and naïve mice. If our hypothesis holds true, one might expect that 
inhibiting $\mathrm{PV}^{+}$interneurons in maternal mice abolish, at least partially, the enhanced spiking suppression of neurons tuned to low frequencies. Opposite, activating $\mathrm{PV}^{+}$interneurons in naïve mice might reproduce the effects observed in maternal mice. It is possible that the suggested effects mediated by $\mathrm{PV}^{+}$interneurons are circuit and target specific, and thus, a broad increase or decrease in $\mathrm{PV}^{+}$interneuron activity might not fully reproduce the effects occurring with auditory learning, but it would nevertheless provide insight into whether they are involved in auditory learning.

So far, we have entertained the hypothesis that $\mathrm{PV}^{+}$ interneurons could be the mechanism and site of plasticity resulting in the effects observed by Shepard et al. (2016). However, one might ask whether $\mathrm{PV}^{+}$interneurons is the exclusive site of plasticity or, alternatively, whether changes in inhibition onto principal cells is merely a passive reflection of plasticity occurring earlier in the auditory pathway. Cortical $\mathrm{PV}^{+}$interneurons receive feed-forward excitatory barrages from thalamic glutamatergic neurons (Harris and Mrsic-Flogel, 2013), and activity changes here could in turn change inhibition in a target-specific manner. The thalamus has traditionally been described as a passive relay hub, passively receiving and transmitting sensory information for the cortex. However, it is now recognized that also thalamus and thalamic activity can undergo experiencedependent plastic changes (Kaas, 1999; Miller and Knudsen, 2003). In mice, the auditory part of the thalamus, the ventral medial geniculate body, also possess tonotopic map organization (Barkat et al., 2011). Hence, for probing whether plasticity occurs before ACtx, when mouse mothers learn the importance of ultrasound frequencies, a future experiment could be to record spiking along the thalamic tonotopic axis in mothers and naîve mice. If differences in thalamic spiking activity is present in mothers compared with naïve mice, when presented with ultrasound frequencies, this could suggest that changes in thalamic feed-forward excitatory barrages onto cortical $\mathrm{PV}^{+}$interneurons could be explanatory for the findings by Shepard et al. (2016). Opposite, if thalamic activity shows no difference between these two groups, this would suggest that auditory learning results from de novo cortical plasticity and computations. Gaining experimental insight on this issue will likely not only be restricted to auditory processing but also extend well into the more canonical functional organization and universal motifs for how experience-dependent sensory plasticity occurs in the brain.

In summary, by employing careful experimental investigations, Shepard et al. (2016) demonstrate that auditory learning of USVs does not require tonotopic map expansion but rather appears to be mediated by increased inhibition of principal cells tuned to low-frequency sounds. In this way, the work by Shepard et al. (2016) challenges the notion that sensory learning is manifested in the cortex as expansions of map area devoted to the learned sensory stimulus. These findings are truly intriguing, and future experiments should aim at elucidating the cellular substrate(s) for this observation. Here, we propose that $\mathrm{PV}^{+}$interneurons could be such a substrate but also that thalamic plasticity could be involved. The study by Shepard et al. (2016) thus paves the way for future research aiming at investigating and under- standing the detailed mechanisms underlying sensory learning and experience-dependent cortical plasticity.

\section{References}

Allene C, Lourenço J, Bacci A (2015) The neuronal identity bias behind neocortical GABAergic plasticity. Trends Neurosci 38:524534. CrossRef Medline

Barkat TR, Polley DB, Hensch TK (2011) A critical period for auditory thalamocortical connectivity. Nat Neurosci 14:1189-1194. CrossRef Medline

Bieszczad KM, Weinberger NM (2010) Remodeling the cortex in memory: increased use of a learning strategy increases the representational area of relevant acoustic cues. Neurobiol Learn Mem 94:127-144. CrossRef Medline

Deisseroth K (2015) Optogenetics: 10 years of microbial opsins in neuroscience. Nat Neurosci 18:1213-1225. CrossRef Medline

Galindo-Leon EE, Lin FG, Liu RC (2009) Inhibitory plasticity in a lateral band improves cortical detection of natural vocalizations. Neuron 62:705-716. CrossRef

Harris KD, Mrsic-Flogel TD (2013) Cortical connectivity and sensory coding. Nature 503:51-58. CrossRef Medline

Hubel DH, Wiesel TN (1974) Sequence regularity and geometry of orientation columns in the monkey striate cortex. J Comp Neur 158:267-293. CrossRef Medline

Hubel DH, Wiesel TN (1977) Ferrier lecture. Functional architecture of macaque monkey visual cortex. Proc R Soc Lond B Biol Sci 198:1-59. Medline

Kaas JH (1999) Is most of neural plasticity in the thalamus cortical? Proc Natl Acad Sci USA 96:7622-7623. Medline

Kaplan ES, Cooke SF, Komorowski RW, Chubykin AA, Thomazeau A, Khibnik LA, Gavornik JP, Bear MF (2016) Contrasting roles for parvalbumin-expressing inhibitory neurons in two forms of adult visual cortical plasticity. Elife 5.pii:e11450. CrossRef

Kato HK, Gillet SN, Isaacson JS (2015) Flexible sensory representations in auditory cortex driven by behavioral relevance. Neuron 88:1027-1039. CrossRef Medline

Kurkela JL, Lipponen A, Hämäläinen JA, Näätänen R, Astikainen P (2016) Passive exposure to speech sounds induces long-term memory representations in the auditory cortex of adult rats. Sci Rep 6:38904. CrossRef Medline

Miller GL, Knudsen El (2003) Adaptive plasticity in the auditory thalamus of juvenile barn owls. J Neurosci 23:1059-1065. Medline

Penfield W, Boldrey E (1937) Somatic motor and sensory representation in the cerebral cortex of man as studied by electrical stimulation. Brain 60:389-443. CrossRef

Pienkowski M, Eggermont JJ (2011) Cortical tonotopic map plasticity and behavior. Neurosci Biobehav Rev 35:2117-2128. CrossRef Medline

Rauschecker JP (1998) Cortical processing of complex sounds. Curr Opin Neurobiol 8:516-521. Medline

Rutkowski RG, Weinberger NM (2005) Encoding of learned importance of sound by magnitude of representational area in primary auditory cortex. Proc Natl Acad Sci USA 102:13664-13669. CrossRef Medline

Schreiner CE, Polley DB (2014) Auditory map plasticity: Diversity in causes and consequences. Curr Opin Neurobiol 24:143-156. CrossRef Medline

Scott SK, Johnsrude IS (2003) The neuroanatomical and functional organization of speech perception. Trends Neurosci 26:100-107. CrossRef Medline

Shepard KN, Chong KK, Liu RC (2016) Contrast enhancement without transient map expansion for species-specific vocalizations in core auditory cortex during learning. eNeuro 3:1-13. CrossRef Medline

Weinberger NM (1997) Learning-induced receptive field plasticity in the primary auditory cortex. Semin Neurosci 9:59-67. CrossRef

Weinberger NM (2004) Specific long-term memory traces in primary auditory cortex. Nat Rev Neurosci 5:279-290. CrossRef Medline

Winer JA, Miller LM, Lee CC, Schreiner CE (2005) Auditory thalamocortical transformation: Structure and function. Trends Neurosci 28:255-263. CrossRef Medline 